\title{
A regional quality control trial of folate assays
}

\author{
D. W. DAWSON AND D. A. NEWSOME
}

From the Department of Haematology, North Manchester General Hospital, Manchester M8 6RB

SUMMARY A regional quality control trial of folate assays is described. It is concluded that the trial is practical and useful in allowing inter-laboratory comparison of results, promoting discussion, and $\stackrel{\mathcal{B}}{\circ}$ improving precision but it is impossible to assess accuracy. It was of no use in the comparison of ? assay methods, probably on account of the small number of laboratories participating.

Folate assays have received much criticism concerning accuracy, precision, inter-laboratory variance, and correlation with the clinical state of the patient.

Variations in technique have been explored, notably the introduction of a chloramphenicolresistant lactobacillus (Davis et al., 1970), but not necessarily with better results (Cooper, 1973). It was, therefore, thought that this was a suitable assay for an inter-laboratory quality control scheme which might help the participants to judge their own performance. Four years ago we organised such a scheme in the former Manchester region.

\section{Organisation of the regional scheme}

Initially, 19 laboratories in the region were invited to participate; only one laboratory declined. The laboratories were issued with numbers to preserve anonymity although it was accepted that we should be able to identify participants. More recently, 11 laboratories from outside the region have joined the scheme.

Specimens are sent to the participating laboratories at intervals of approximately three months. Results are to be returned within three weeks. Twenty-six sera and two blood lysates have been sent out so far. The specimens are treated with ascorbic acid before dispatch. No bacteriostatic agent is added. Two of the sera and one of the lysates were freeze-dried. In the six most recent trials, recovery experiments were undertaken; specimens were sent out in duplicate, one portion having a known amount of folic acid, prepared according to Chanarin (1969), added. Each participant was sent a questionnaire about the method of assay, serum dilution tested, duration of incubation, and normal range.

Received for publication 21 September 1976
When results are returned they are recorded 0 against the laboratory number. The mean and standard deviation (SD) are calculated. Those results $>$ lying outside $3 \mathrm{SD}$ are discarded and a corrected mean and SD are recalculated. A variance index is $\vec{\varphi}$ then calculated for each laboratory, one unit equal- $\forall$ ling $1 \mathrm{SD}$ from the corrected mean to a maximum of 4. A cumulative mean variance index (MVI) is also determined for each laboratory after every trial. Two forms are sent out within 10 days of the last date of return of results. One (Table 1) lists the individuals'

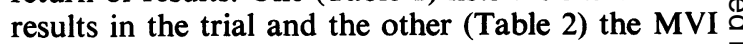
for each laboratory and the average for all the $\overrightarrow{\overrightarrow{0}}$ participants (overall MVI).

\section{Results}

There was a $77 \%$ return for the first 28 specimens. One trial was unsatisfactory because of bacterial contamination of the sample. From one early trial insufficient returns were obtained for meaningful $\mathrm{O}$ analysis.

The normal range quoted by the participants $\frac{D}{0}$ varied greatly. The lower limit lay between 1 and 5 . $\mu \mathrm{g} / 1$ and the upper between 5 and $25 \mu \mathrm{g} / \mathrm{l}$. It was, $\sigma$ therefore, necessary to assess the trial returns against $N$ the ranges quoted before comparing the returns with each other. No correlation between the individual $\sigma$ results and the quoted normal range emerged. In six consecutive trials, nine laboratories, recording a lower limit of $3 \mu \mathrm{gl}$ or less, gave a mean of $6.9 \mu \mathrm{g} / 1, \stackrel{\infty}{\stackrel{\Phi}{\sim}}$ whereas seven, with a lower limit of more than $3 \mu \mathrm{g} / 1$, gave a mean of $6.7 \mu \mathrm{g} / \mathrm{l}$. The results in recovery experiments did not relate either to the quoted lower $\stackrel{\mathbb{D}}{\mathbb{D}}$ limit or to the extent of the ranges. Of the laboratories $\frac{?}{\mathbb{D}}$ quoting specific limits, five with a range of less than 2 $14 \mu \mathrm{g} / \mathrm{l}$ gave a mean recovery of $4.2 \mu \mathrm{g} / \mathrm{l}$ and five with 
Table 1 Individual laboratory results: extract of report sheet June 1975

\begin{tabular}{|c|c|c|c|}
\hline \multirow[t]{2}{*}{ Laboratory No. } & \multicolumn{2}{|c|}{ Serum folate $(\mu \mathrm{g} / l)$} & \multirow{2}{*}{$\begin{array}{l}\text { Difference } \\
F A \text { 23-FA } 24\end{array}$} \\
\hline & $F A 23$ & $F A 24$ & \\
\hline $\begin{array}{r}2 \\
3 \\
4 \\
5 \\
22\end{array}$ & $\begin{array}{r}11 \cdot 3 \\
3 \cdot 2 \\
10 \cdot 2 \\
10 \cdot 8 \\
23 \cdot 0\end{array}$ & $\begin{array}{r}8.8 \\
6.5 \\
9.0 \\
7.0 \\
11.8\end{array}$ & $\begin{array}{r}2.5 \\
-3.3 \\
1.2 \\
3.8 \\
11.2\end{array}$ \\
\hline $\begin{array}{l}\text { Mean } \\
\text { SD } \\
\text { n }\end{array}$ & $\begin{array}{c}11 \cdot 1 \\
4 \cdot 6 \\
19\end{array}$ & $\begin{array}{c}8 \cdot 2 \\
2 \cdot 7 \\
19\end{array}$ & $3 \cdot 1$ \\
\hline
\end{tabular}

Comment: FA 23 was FA 24 to which $3 \mu \mathrm{g} / 1$ of folic acid had been added.

a range of more than $17 \mu \mathrm{g} / \mathrm{l}$ gave a mean recovery of $3 \cdot 8 \mu \mathrm{g} / 1$.

These findings show that the limits of the normal ranges quoted did not relate to the results; for example, two laboratories with every result within 1 SD of the mean for the first 12 trials recorded very different normal ranges of 3-8 $\mu \mathrm{g} / 1$ and $7-15.9 \mu \mathrm{g} / 1$. All trial results were, therefore, considered together, and the Figure shows the steady improvement in the overall MVI. The cumulative MVI of the individual participants after 28 trials varied from 0.04 to 0.75 .

The trial results were compared with the assay technique used. Of the original participants, five used the technique of Waters and Mollin (1961), three the aseptic addition method of Herbert (1966), and 14 a chloramphenicol-resistant organism (Davis et al., 1970). The cumulative MVI of those laboratories using the aseptic technique was the lowest $(0 \cdot 27)$ and that of those using the method of Waters and Mollin (1961) the highest $(0 \cdot 42)$, but the difference was not significant. Nor did any detail of the assay, as listed in the questionnaire, correlate with the MVI results.

\section{Discussion}

The aims of this trial were:

1 To allow participants to judge their performance by comparing their results with those of other laboratories;
2 to improve accuracy and precision;

3 to promote discussion of results and techniques;

4 to compare assay methods.

We feel that we have succeeded in the first and third of these aims. Laboratories which found that they had a poor MVI have consulted us about their techniques and two laboratories have asked us to take over their assays. Inter-laboratory discussion has been helped by the regional basis of the trial as many members of staff in the laboratories knew each other.

The trial has too few participants to be used for investigating folate assay techniques. Comparison of the basic methods was unsuccessful because of the disproportionate number of laboratories using the assay employing a chloramphenicol-resistant organism. The small number of participants is a disadvantage in a regional scheme and is one reason why we wish to enlarge the trial.

Correlation between low upper limits to the quoted normal ranges and high serum dilution in the assay might have been expected (Millbank et al., 1970) but was not found. This could be due to the trial being

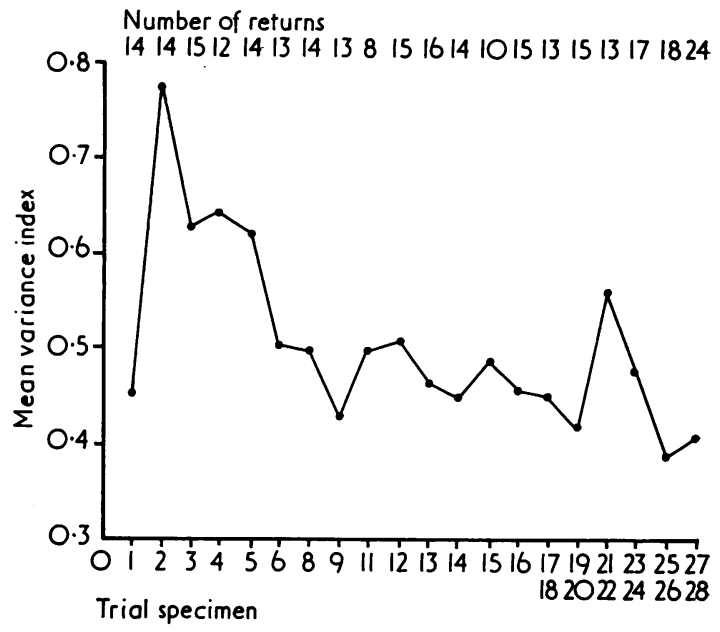

Figure Change in overall MVI.

Table 2 Individual and overall MVIs: extract of report sheet June 1975

\begin{tabular}{|c|c|c|c|c|c|}
\hline \multirow[t]{2}{*}{ Laboratory No. } & \multicolumn{5}{|l|}{ Serum No. } \\
\hline & $F A 16$ & $F A 17+18$ & $F A 19+20$ & $F A 21+22$ & $F A 23+24$ \\
\hline $\begin{array}{l}2 \\
3 \\
4 \\
5 \\
22 \\
\text { Overall MVI }\end{array}$ & $\begin{array}{l}0.26(12) \\
0.34(12) \\
0.89(14) \\
0.22(10) \\
1.00 \quad(1) \\
0.46\end{array}$ & $\begin{array}{l}0.27(12) \\
0.43(14) \\
0.77(16) \\
0.18(12) \\
1.00 \quad(2) \\
0.45\end{array}$ & $\begin{array}{l}\overline{0.38}(16) \\
0.75(18) \\
0.15(14) \\
0.50 \quad(4) \\
0.44\end{array}$ & $\begin{array}{l}0.22(14) \\
0.34(18) \\
0.68(20) \\
0.14(16) \\
0.50 \quad(6) \\
0.57\end{array}$ & $\begin{array}{l}0.19(16) \\
0.31(20) \\
0.61(22) \\
0.12(18) \\
0.75 \quad(8) \\
0.49\end{array}$ \\
\hline
\end{tabular}

Figures in parentheses show the number of specimens which the laboratory has assayed. 
too small but it may also be because some laboratories have not estimated their own normal ranges, suggested by their failure to record an upper limit.

It is difficult to assess improvements in accuracy and precision in an assay in which the true result is unknown. A good performance in the recovery experiments shows only that extrinsic folic acid is being measured accurately and not necessarily serum methyl folate. The steadily improving overall MVI shows that greater precision is being obtained throughout the region. Individual laboratories have been encouraged by seeing their own cumulative MVI improve.

It would be possible for a laboratory to produce results which differ from the mean by a constant amount in all trials; no improvement in its cumulative MVI would be seen but its service would be acceptable provided it had assessed its own normal range. We could not, however, identify any correlation between the results of the trials and the quoted normal ranges, suggesting that those laboratories with a high MVI were imprecise in their results.

As far as the organisation of the trial is concerned the main fault was the failure of laboratories to put their number on the questionnaire. The distribution of the relatively small number of specimens required in the trial has been practical, and we should like to increase the number of participants to 50 to give a balance between the work involved in the preparation of specimens and the amount of information obtained from the results. The collection, preparation, and dispensing of the samples, together with the statistical processing of the results, takes about 6 hours of technician time and $1 \frac{1}{2}$ hours of clerical time for each trial. The cost of the trials, including postage and vials, is about $£ 90-100$ per annum. The volume of serum required for trials with 50 participants would be $200 \mathrm{ml}$. This would have to be doubled if betweenbatch precision tests were included, an improvement we intend to make. All specimens should be tested for HBsAg.

It has been difficult to know what sera to issue. It is desirable to test around the level of clinical significance but the SD of a mean at this level for few results is such that any below the mean is likely to be acceptable. However, by sending duplicate specimens with a known amount of folic acid added to one, we 을 have been able to test at a low level and have a second, higher reading, in the range covered by the $\stackrel{\vec{\sim}}{\stackrel{9}{\circ}}$ standard dilutions used in most laboratories. Not all $\mathrm{O}$ radioligand assay techniques are, however, suitable 흠 for assay of folic acid. As well as liquid samples we $\frac{\bar{T}}{\vec{D}}$ have tried three freeze-dried materials. Lyophylisation $\stackrel{\mathbb{Q}}{\propto}$ was time-consuming but produced a satisfactory sample. Two commercial preparations have been tried. A lyophylised horse serum (Wellcome) gave a low result in every laboratory with a mean of $1.4 \vec{\omega}$ $\mu \mathrm{g} / 1$ despite the stated level of $6 \cdot 1 \mu \mathrm{g} / \mathrm{l}$. The other preparation, a lyophylised haemolysate from Arm- $\overrightarrow{8}$ trol, was satisfactory with a mean of $10.7 \mu \mathrm{g} / \mathrm{l} \dot{\omega}$ (stated level 9.8 $\mu \mathrm{g} / \mathrm{l}$ ) although this, and four other diluted haemolysates, gave greater variation in $\omega$ results than sera of comparable folate levels.

We believe that the most satisfactory scheme for 윽 quality control of folate assays for the country as a whole would be for two or three regions to group $\frac{7}{0}$ together, one centre correlating the results, and for there to be liaison between these centres.

We wish to thank our colleagues who put up with the initiation and continuation of this trial.

\section{References}

Chanarin, I. (1969). The Megaloblastic Anaemias, p. 311. Blackwell Scientific Publications, Oxford and Edinburgh.

Cooper, B. A. (1973). Superiority of simplified assay for folate with Lactobacillus casei ATCC 7469 over assay with a chloramphenicol-adapted strain. Journal of Clinical Pathology, 26, 963-967.

Davis, R. E., Nicol, D. J., and Kelly, A. (1970). An automated method for the measurement of folate activity. Journal of Clinical Pathology, 23, 47-53.

Herbert, V. (1966). Aseptic addition method for Lactobacillus casei assay of folate activity in human serum. Journal of Clinical Pathology, 19, 12-16.

Millbank, L., Davis, R. E., Rawlins, M., and Waters, A. H. (1970). Automation of the assay of folate in serum and whole blood. Journal of Clinical Pathology, 23, 5459.

Waters, A. H. and Mollin, D. L. (1961). Studies on the folic acid activity of human serum. Journal of Clinical Pathology, 14, 335-344. 